\title{
EFFECT OF DROUGHT STRESS ON WATER RELATION TRAITS OF FOUR SOYBEAN GENOTYPES
}

\author{
J.A. Chowdhury ${ }^{1}$, M.A. Karim ${ }^{2}$, Q.A. Khaliq ${ }^{2}$, A.U. Ahmed ${ }^{3 *}$ and \\ A.T.M.A.I. Mondol ${ }^{4}$ \\ ${ }^{1}$ Agronomy Division, Bangladesh Agricultural Research Institute, Gazipur-1701, Bangladesh \\ ${ }^{2}$ Department of Agronomy, Bangabandhu Sheikh Mujibur Rahman Agricultural University \\ Gazipur-1706, Bangladesh \\ ${ }^{3}$ Plant Pathology Division, Bangladesh Agricultural Research Institute, Gazipur-1701, Bangladesh \\ ${ }^{4}$ Soil Science Division, Bangladesh Agricultural Research Institute, Gazipur-1701, Bangladesh
}

\begin{abstract}
An experiment was conducted in a venyl house at the environmental stress site of Bangabandhu Sheikh Mujibur Rahman Agricultural University during September to December 2012 to know the internal water status under drought stress in soybean genotypes, viz. Shohag, BARI Soybean-6, BD2331 (relatively stress tolerant) and BGM2026 (susceptible). Drought (water) stress reduced the leaf water potential in all the genotypes though was more negative in tolerant genotypes than in susceptible ones. The lowest leaf water potential was obtained from BARI Soybean-6 (-1.58 MPa) and the highest in BGM2026 (-1.2 MPa). Relative water content (RWC) decreased remarkably in all the genotypes and reduction was more in susceptible than tolerant genotypes. At 8.00 am, RWC of stressed plants decreased by $9.58,9.02,8.90$ and $13.90 \%$ in the genotype Shohag,, BARI Soybean-6, BD2331 and BGM2026 at vegetative stage, respectively. Drought stress decreased the exudation rate in all the genotypes of soybean and it was $24,27,22$ and $12 \mathrm{mg} \mathrm{h}^{-1}$ in the genotype Shohag, BARI Soybean-6, BD2331 and BGM2026 at vegetative stage, respectively. Leaf temperatures in drought stressed plant were higher than in well-watered plants. Shohag, BARI Soybean-6, BD2331 and BGM2026 showed 4.7, 4.5 5.2 and $11.07 \%$ increase in leaf temperature due to water stress. At drought stressed treatment reduction in leaf water potential, relative water content, exudation rate and water retention capacity were noticed at the three growth stages in all the genotypes with a concurrent increase in leaf temperature. Genotypes BARI Soybean-6, Shohag and BD2331 showed considerably less reduction in relative water content, exudation rate and water retention capacity, high reduction in leaf water potential and less increase in leaf temperature during drought were considered as drought tolerant. However genotype BGM2026 showed considerably high reduction in
\end{abstract}

* Corresponding author e-mail: kajalashraf@gmail.com 
relative water content, exudation rate and water retention capacity, low reduction in leaf water potential and high increase in leaf temperature was considered as drought susceptible.

Keywords: Drought, stress, soybean, genotypes

\section{INTRODUCTION}

Water is absolutely necessary for the functioning of protoplasm of cell. Water deficit stress affects water status in plant. Thus adequacy and inadequacy of water are the limiting factors for life both in land and water environment (Onwugbuta-Enyi, 2004). Several methods are used to characterize plant water status under water stress conditions. Determination of water relation components in whole plant or cellular level is important for determination of tolerance genotypes to environmental stresses especially to water deficit stress. It may be possible to improve the water stress tolerance of soybean by understanding the water relation parameters that are associated with high productivity. Among the several methods used to characterize internal plant water status under water stress conditions, relative water content and leaf water potential are used as the indicators of degree of water stress. The adequacy and inadequacy of water reflects on the status of plant water relations viz. leaf water potential, relative water content, exudation rate etc. of a plant and decrease them (Omae et al., 2007). Leaf water potential and relative water content are useful means for determining the physiological water status of plants (Gonzales \& Gonzales-Vilar, 2001). Thus an understanding of the influence of drought on leaf water relations is crucial for classifying the mechanism of drought tolerance of a plant (Omae et al., 2007).

Leaf water potential is considered to be a reliable parameter for quantifying plant water stress response. Nayyer et al. (2005) has suggested that the leaf water potential is a prominent character that can be selected for improving drought tolerance of different crops. Jones in 1990 revealed that a majority of workers used leaf water potential to measure plant water status. Leaf water potential expresses the totality of turgor and osmotic potentials and under drought stress, adjustment in osmotic potential or maintenance of turgor could result in the maintenance of leaf water potential (Ocampo and Robles, 2000). The potential varies greatly, depending on the type of plant and environmental conditions. Water stressed plants showed a marked reduction in xylem exudation rate compared to well-watered condition (Aziz, 2003). Leaf temperature is also related to water stress. Ehrler et al. (1978) reported that canopy temperature provides a good indication of plant water potential. This study was initiated to determine and compare the variations in the internal water status of four soybean genotypes due to drought. 


\section{MATERIALS AND METHODS}

A pot experiment in a vinyl house was conducted at the Bangabandhu Sheikh Mujibur Rahman Agricultural University during September to December 2012. Three relatively water stress tolerant (Shohag, BARI Soybean-6 and BD2331) and one susceptible (BGM-2026) genotypes, selected from the previous experiment, were used in this study to know the internal water status under drought stress in soybean. Seeds of tolerant and susceptible genotypes were sown in plastic pots. The soil of the pot was filled with mixture of soil and cow dung at a ratio of $4: 1$. Pot contained 12.0 $\mathrm{kg}$ of soil which was equivalent to $9 \mathrm{~kg}$ oven dry soil and holds about $28 \%$ moisture at field capacity (FC). Soil used in the pot was sandy loam. The soil of the pot was fertilized uniformly with $0.15,0.18,0.36$ and $0.1 \mathrm{~g}$ urea, triple super phosphate, muriate of potash and gypsum corresponding to 24-30-60-15 kg NPKS per hectare, respectively. Six seeds pot ${ }^{-1}$ were sown on 3 September, 2012. After seedling establishment two uniform and healthy plants pot $^{-1}$ were allowed to grow. Two watering treatments of the plants viz. drought stress (water stress) (50\% water of the FC) and non-stress (control) (80\% water of FC) were applied at 21 days after emergence (DAE) and maintained throughout the growing season. The pots were arranged in a completely randomized design (factorial) with four replications (two plants pot $^{-1}$ considered as one replication). There were eight treatment combinations, including four genotypes and two water regime treatments (hereafter referred to as non-stress and water stress treatments). Normal management practices (Khan, 2013) were applied for all the treatments.

\section{Data were collected on the following parameters \\ Relative water content (RWC) in leaf}

Relative water content (RWC) of leaves was measured at vegetative, flowering and pod development stages of each genotype at 8:00 am and 1:00 pm. Fully developed $3^{\text {rd }}$ leaf from the top was used for RWC measurement. Immediately after cutting, leaves were sealed within plastic bags and kept in ice box and quickly transferred to the laboratory. The fresh weight of leaves from each treatment was recorded just after removal. Turgid weight (TW) was obtained after soaking leaves in distilled water in beakers for 24 hours at room temperature (about $20^{\circ} \mathrm{C}$ ) and under low light condition of the laboratory. After soaking, leaves were quickly and carefully blotted dried with tissue paper in preparation for determining turgid weight. Dry weight (DW) of the leaf was obtained after oven drying the leaf samples for 72 hour at $70^{\circ} \mathrm{C}$. RWC was calculated using the formula of Schonfeld et al. (1988):

RWC $(\%)=($ FW - DW $) /($ TW - DW $) \times 100$

Where, $\mathrm{FW}=$ Fresh weight

DW $=$ Dry weight

TW $=$ Turgid weight 
Water retention capacity (WRC) were calculated as follows (Sangakkara et al., 1996).

Turgid weight

Water retention capacity $(\mathrm{WRC})=$

Dry weight

\section{Leaf water potential}

Leaf water potential was measured at 6:30 am with the help of Scholander Pressure Bomb apparatus. The third uppermost fully expanded leaf was cut carefully with sharp blade from 4 replicated plants of each treatment. The petiole of cut leaf was set in the apparatus and pressure was applied to the leaf from a cylinder of compressed gas until xylem sap appeared at the cut surface of the leaf (detected by using a magnifying glass). The gas flow was immediately stopped and the pressure was noted in the gauge.

\section{Xylem exudation rate $(X E R)$}

Xylem exudation rates at vegetative, flowering and pod development stages were measured at 9:00 am at $5 \mathrm{~cm}$ above from stem base. At first, dry cotton was weighed. A slanting cut on stem was made with a sharp knife. Then the weighed cotton was placed on the cut surface. The exudation of sap was collected from the stem for 1 hour at normal temperature. The final weight of the cotton with sap was taken. The exudation rate was calculated by deducting cotton weight from the sap containing cotton weight and expressed per hour basis as follows;

$$
\text { Xylem exudation rate }=\frac{(\text { Weight of cotton }+ \text { sap })-(\text { Weight of cotton })}{\text { Time }} \mathrm{mg} \mathrm{h}^{-1}
$$

\section{Statistical analysis}

The data were analyzed by MSTAT-C statistical program. The difference between the treatments means were compared by Least Significant Difference (LSD) test (Gomez and Gomez, 1983).

\section{RESULTS AND DISCUSSION}

\section{Leaf water potential}

Water stress decreased the leaf water potential (LWP) at pod development stages studied in all the four soybean genotypes (Figure 1). Water stress significantly reduced leaf water potential of soybean plant and the potentials fell from $-0.88 \mathrm{MPa}$ in unstressed leaves to -1.18 MPa in drought stressed leaves (Makbul et al., 2011). Other researchers also reported that leaf water potential decreased under drought stress conditions (Siddique et al., 2000). Such observation also observed in snap bean by Omae et al. (2007) and in soybean by Ohashi et al. (2000). Leaf water potential in all the genotypes was higher under control condition than that in stress condition. 
Under stress condition the LWP of BARI Soybean-6 was more negative which was followed by Shohag and BD2331 and the minimum in BGM2026. The leaf water potential recorded at pod development stage varied from -1.00 to $-1.2 \mathrm{MPa}$ and from -1.2 to $-1.58 \mathrm{MPa}$ under non-stress and water stress condition, respectively. Under water stress condition the lowest leaf water potential was obtained from BARI Soybean-6 (-1.58 MPa) and the highest in BGM2026 (-1.2 MPa). The highest reduction in leaf water potential $31.66 \%$ was recorded in BARI Soybean-6. The changes in water potential might be due to change in osmotic pressure, the osmotic components of water. Gonzalez et al. (2008) recorded a significant decrease in leaf water potential under drought stress in barley.

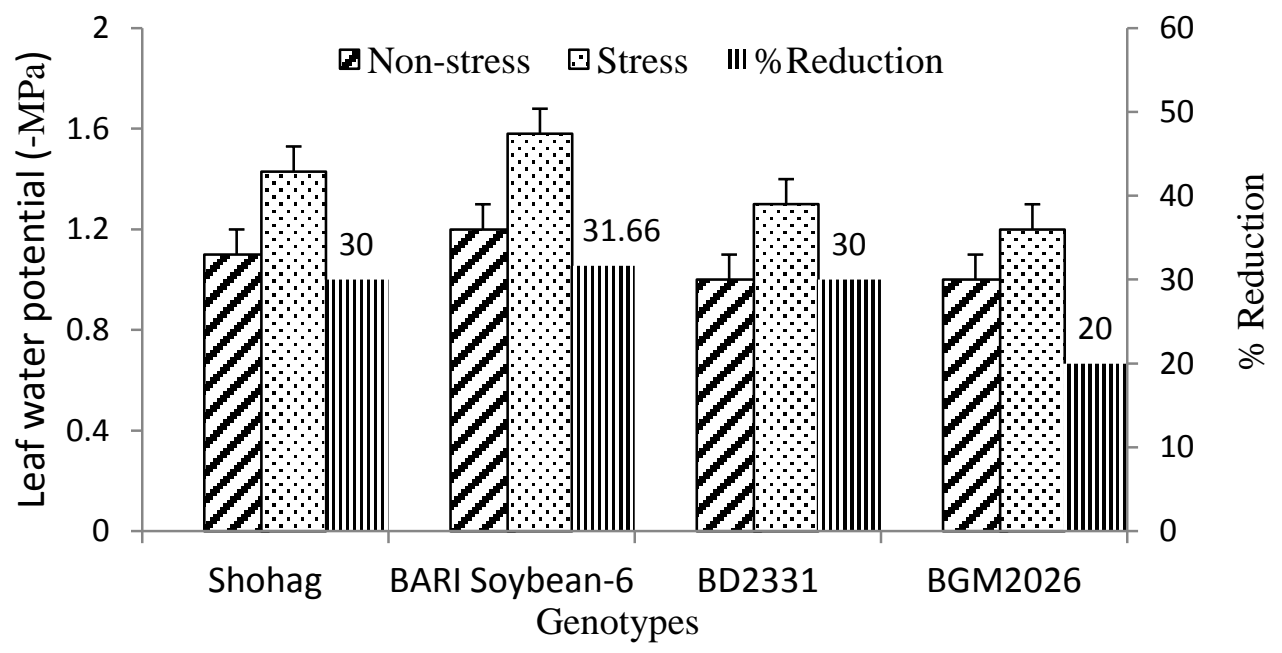

Figure 1. Leaf water potential in soybean at pod development stage as affected by two water regimes [Vertical bar represent LSD value at 5\% level of significant]

\section{Relative leaf water content}

Relative water content (RWC) is an important determinant of metabolic activity and survival of leaf. RWC values of four genotypes at three different stages are shown in figures 2, 3 and 4. Water stress significantly reduced RWC at two sampling times (8:00am and 1:00 pm) across the genotypes at different growth stages in all the four soybean genotypes studied. The reduction in RWC due to water stress was also reported by Omae et al. (2005) and Omae et al. (2007) in snap bean. Plants grown under water stress conditions showed a lower RWC than those grown under non stress conditions. Relative water content was higher in the morning, while decreased at noon. Several researchers reported that RWC of different crops was the highest in the morning and gradually decreased thereafter (Omae et al., 2005). Schonfeld et al. (1988) reported that the cultivars that were resistant to drought had more RWC. BARI Soybean-6 had higher RWC than the rest of genotypes and genotype 
BGM2026 had the lowest RWC at all the three growth stages under both non-stress and stress condition. Upreti et al. (2000) reported that sensitive pea genotypes were more affected by a decline in relative water content than tolerant ones under drought stress condition. The RWC of all the genotypes fell at noon, possibly due to higher evaporation resulting from increased temperature and light intensity.

Water stress significantly reduced RWC at two sampling times (8:00am and 1:00 pm) across the genotypes at different growth stages in all the four soybean genotypes studied. At $8.00 \mathrm{am}$, RWC of water stressed plants of Shohag decreased by 9.58, 10.32 and $10.94 \%$, BARI Soybean-6 decreased 9.02, 9.84 and 10.65\%, BD2331 decreased 8.90, 11.68 and 12.94\%, and BGM2026 decreased 13.90, 15.31 and $16.21 \%$ compared to control plants at vegetative, flowering and pod development stages, respectively. At $1.00 \mathrm{pm}$, RWC of water stressed plants decreased by 11.21, 12.55 and $13.40 \%$ in Shohag, decreased 10.79, 11.60 and $13.10 \%$ in BARI Soybean$6,12.48,14.27$ and $18.74 \%$ in BD 2331 and 19.22, 21.51 and $25.45 \%$ in BGM2026 at three growth stages, respectively. The higher reduction was found in BGM2026 at both the day time. Similar results were observed by Rosales-Serna et al. (2004) in tolerant cultivar Pinto Villa compared to susceptible cultivar Bayo Madero; which was explained as to be related to the lower stomatal index in the adaxial surface in Pinto Villa in comparison with Bayo Madero (Aguirre et al., 1999), or to a higher capability for soil extraction under drought stress. Parsons and Howe (1984) opined that among several methods used to characterize internal plant water status under drought conditions, RWC is an integrative indicator.

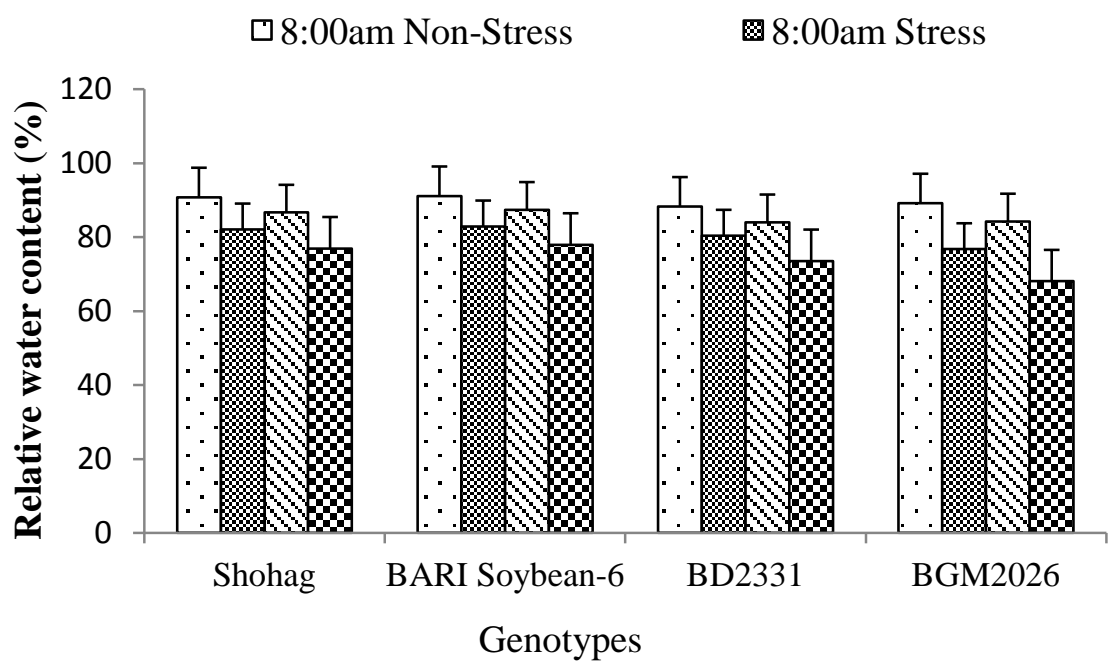

Figure 2. Relative water content (RWC) in soybean genotypes under non-stress and water stress conditions at vegetative stage [Vertical bar represent LSD value at 5\% level of significant] 


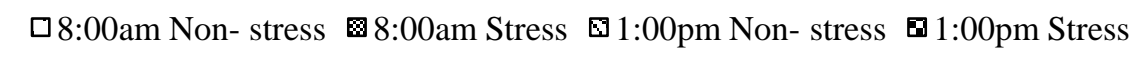

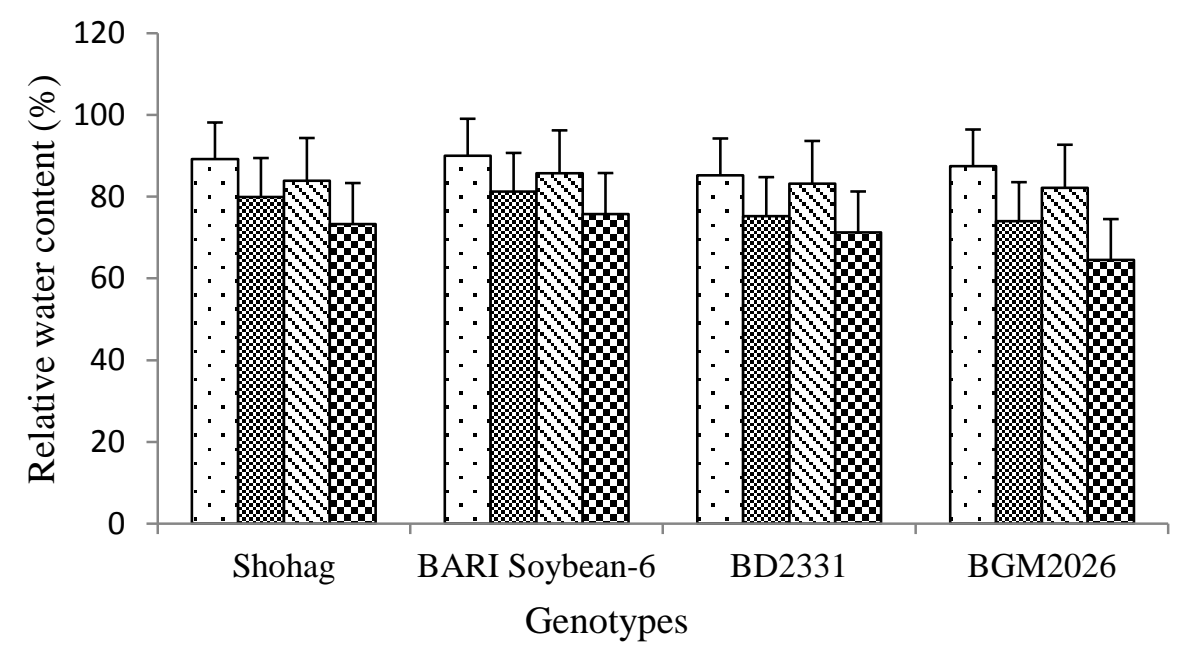

Figure 3. Relative water content (RWC) in soybean genotypes under non-stress and water stress conditions at flowering stage [Vertical bar represent LSD value at $5 \%$ level of significant]

$\square$ 8:00am Non- stress $\mathbf{0}$ 8:00am Stress $\mathbf{Q} 1: 00 \mathrm{pm}$ Non- stress 1:00pm Stress

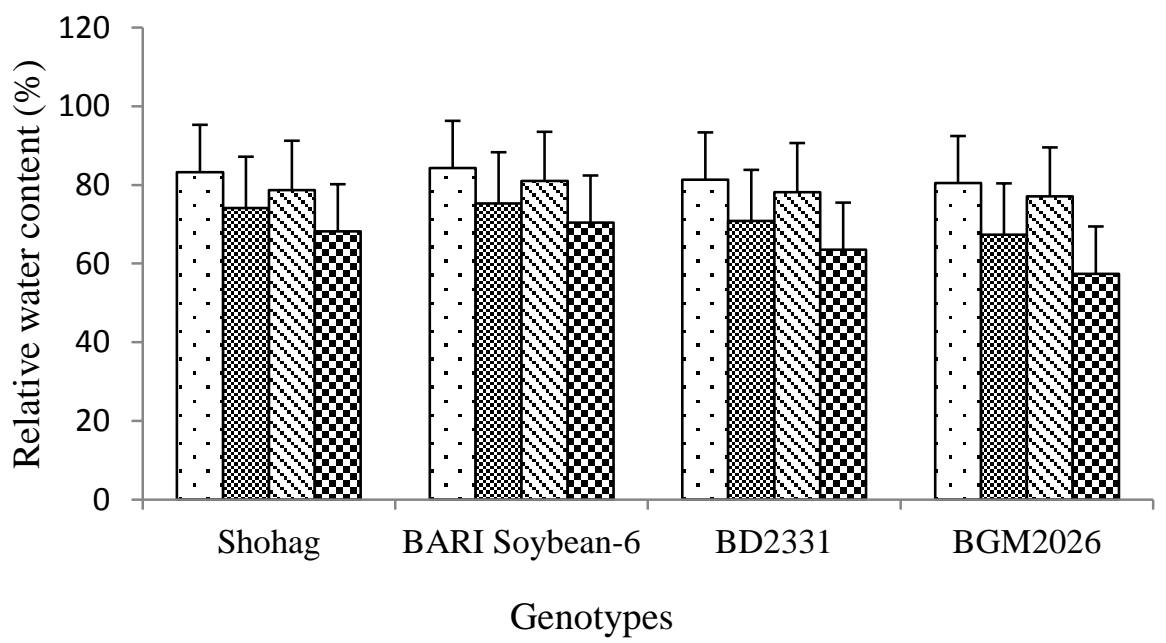

Figure 4. Relative water content (RWC) in soybean genotypes under non-stress and water stress conditions at pod development stage [Vertical bar represent LSD value at $5 \%$ level of significant] 


\section{Water retention capacity}

The turgid weight/dry weight (TW/DW) ratio illustrates the water retention capacity (WRC) of plants that are determined by the cell structures. Plants grown under a high moisture regime maintains a higher ratio and that might be due to the lower destruction of plant tissues by moisture deficit (Sangakkara et al., 1996). Water stress decreased the WRC significantly which was affected more at noon compared to that at morning (Figure 5). Among the genotypes, the WRC ranged from 6.6 to 7.2 and 6.0 to 7.0 at morning and noon respectively under non-stress and from 6.0 to 6.3 and 5.1 to 5.5 at morning and noon, respectively under water stress condition. Genotype BGM2026 presented the highest WRC value under non-stress condition but the lowest under water stress condition and decreased considerably at morning $(16.66 \%)$ and noon $(27.14 \%)$ while Shohag and BARI Soybean-6 presented the lowest TW/DW values under non-stress condition. The reduction rate of WRC was minimal which are $7.57 \%$ for Shohag, $13.33 \%$ for BARI Soybean-6, and $7.57 \%$ for Shohag, and $13.11 \%$ for BARI Soybean-6 at morning and noon, respectively (Figure 6). The higher reduction in WRC for BGM2026 indicated a greater damage in cell structure due to water stress than Shohag and BARI Soybean-6. Sanagakkara et al. (1996) and Martinez et al. (2007) observed similar results in Phaseolus vulgaris. This reduction was also observed in Mediteranean shrub Artiplexhalimus (Martinez et al., 2004). The reduction in the leaf TW/DW could be result of hemi-cellulose and cellulose accumulation in the cell well as reported by Wakabayashi et al. (1997). Martinez et al. (2007) pointed out that there is a negative relationship between TW/DW and drought resistance index (DRI) under water stress. Martinez et al. (2004) also observed that a decrease in the leaf TW/DW indicated a decrease in cell size. A reduction in cell size is one of the most common anatomical changes observed in water stressed leaves (Tardieu et al., 2000). In the present study, Shohag and BARI Soybean-6 showed the lowest reduction in WRC, and thus an indication of their tolerance to water stress.

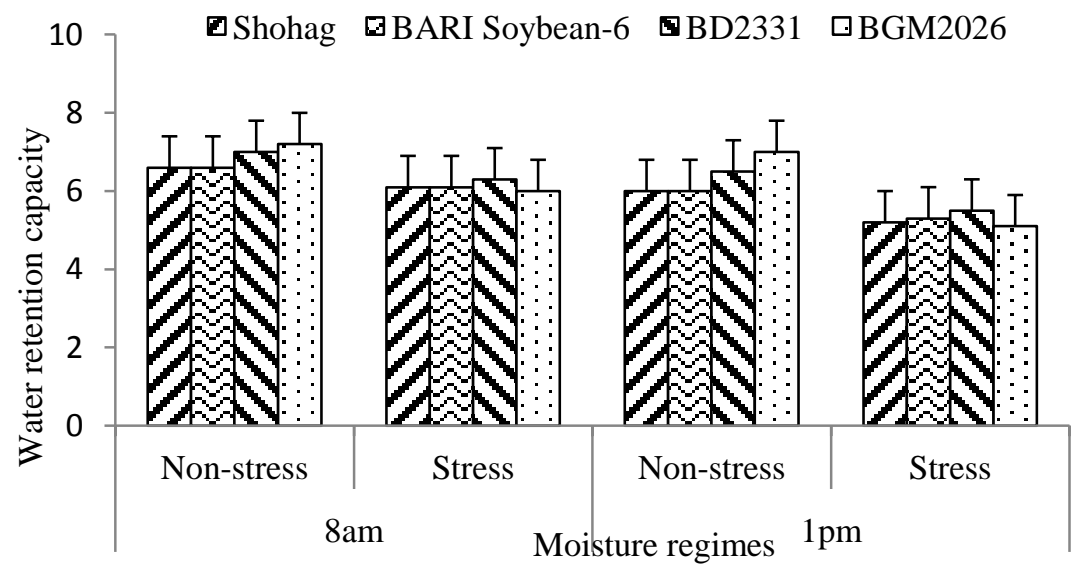

Figure 5. Water retention capacity in four soybean genotypes grown under non-stress and water stress conditions at pod development stage [Vertical bar represent LSD value at $5 \%$ level of significant] 


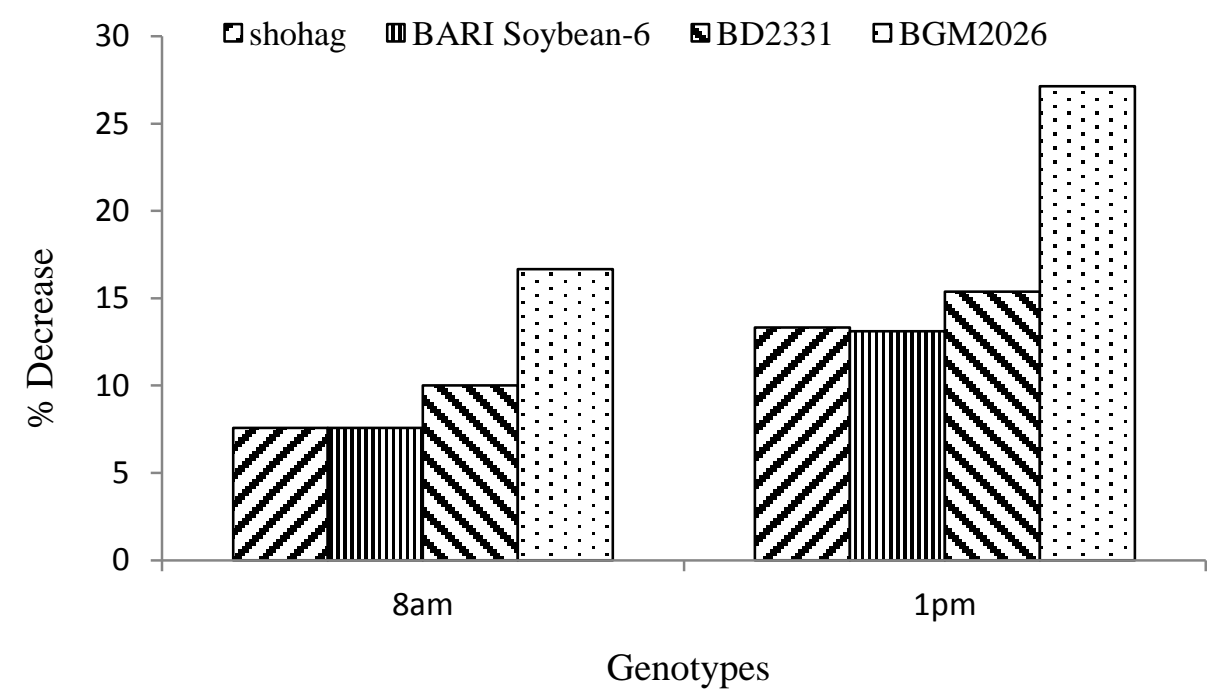

Figure 6. Reduction percent of water retention capacity in four soybean genotypes grown under non-stress and water stress conditions at pod development stage

\section{Xylem exudation rate}

Xylem exudation rate is known as the flow of sap from cut end of stem against the gravitational force. Under normal condition, exudation rate is higher than that under any kind of stress conditions. Thus, the exudation rate can be used as an indicator to measure the severity of water stress. Water stress drastically reduced the exudation rate in all the genotypes at all the growth stages studied. Exudation rate is directly associated with the flow of transpiration. Decreased exudation rate means lower water uptake by the plant. In this experiment it was found that drought stress substantially decreased the exudation rate in all the genotypes of soybean at all the three growth stages studied (Figure 7). The exudation rate in genotype BGM2026 was much lower than that of other genotypes in stressed condition. The exudation rate was not significant under non-stress condition, while marked variation was observed due to water stress irrespective of genotypes. The exudation rate varied from 79 to 82,99 to 107 and 92 to $100 \mathrm{mg} \mathrm{h}^{-1}$ at vegetative, flowering and pod development stages, respectively under non-stress condition and 12 to $27,8.3$ to 20.2 and 4.5 to $16.3 \mathrm{mg} \mathrm{h}^{-1}$ at vegetative, flowering and pod development stage respectively under water stress condition. At all the growth stages, the highest exudation rate was recorded in BARI Soybean-6 which was followed by Shohag and BD2331, while the genotype BGM2026 was affected more and had the lowest exudation rate under water stress condition which indicated that the former three genotypes absorbed more water than that of BGM2026 under water stress condition. 
The reduction percent of exudation rate was the highest in BGM2026 (85.36, 92.24 and $95.5 \%$ at vegetative, flowering and pod development stages respectively) due to the effect of water stress (Figure 8). The results obtained in this study were in agreement with those obtained by Baque (2006) who reported that exudation rate was higher in control and lower in moister stress in wheat. Reduction in water uptake by other plants due to water stress was also reported by Choudhury (2009) in french bean.

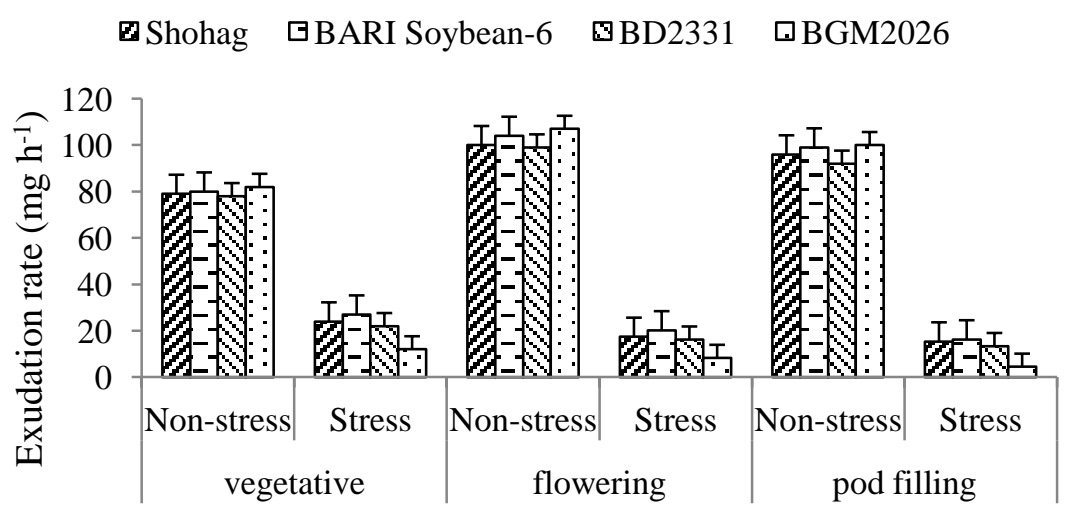

Water regimes

Figure 7. Xylem exudation rate in four soybean genotypes grown under non-stress and water stress conditions at different growth stages [Vertical bar represent LSD value at 5\% level of significant]

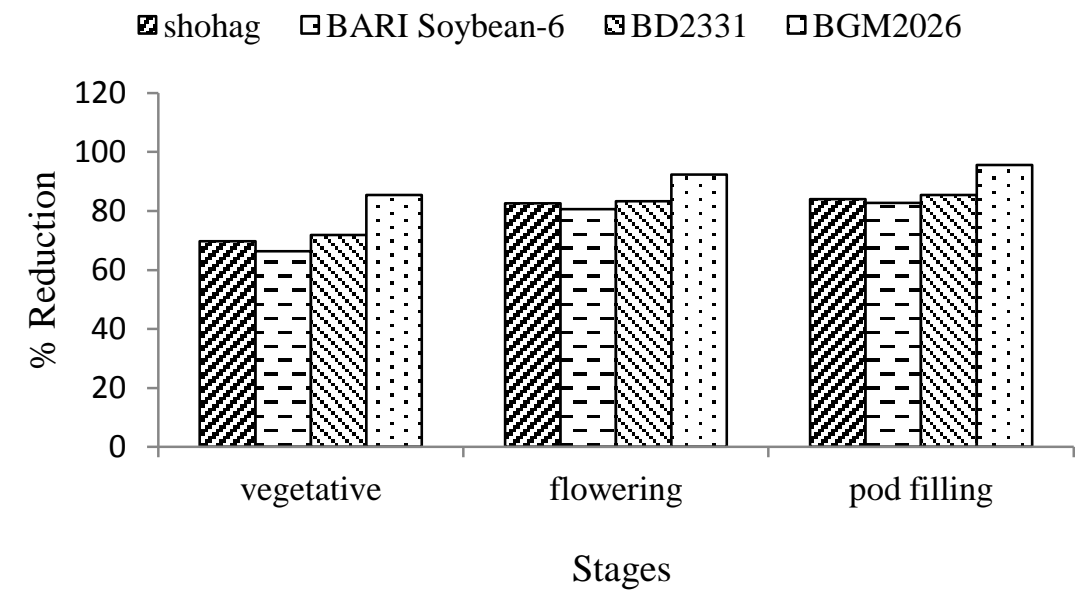

Figure 8. Reduction percent of Xylem exudation rate in four soybean genotypes grown under non-stress and water stress conditions at different growth stage 


\section{Leaf temperature}

Water stress increased the leaf temperature of all the genotypes under study (Figure 9). Leaf temperatures in drought stressed plant were higher than in well-watered plants. Leaf temperature ranged from 34.98 to $39.18^{\circ} \mathrm{C}$ and 36.57 to $41.41^{\circ} \mathrm{C}$ under non-stress and water stress conditions, respectively. Under non-stress environment genotype BD2331 showed the highest leaf temperature, while BGM2026 showed the highest under water stress environment. Shohag, BARI Soybean-6 and BD2331 showed only 4.7, 4.5 and 5.2\% increase in leaf temperature due to water stress while genotype BGM2026 showed $11.07 \%$ increase in leaf temperature. Increase in leaf temperature due to water stress might be attributed to low transpiration under drought. Winter et al. (1988) also found significant difference in leaf temperature between droughts stressed and irrigated plants.

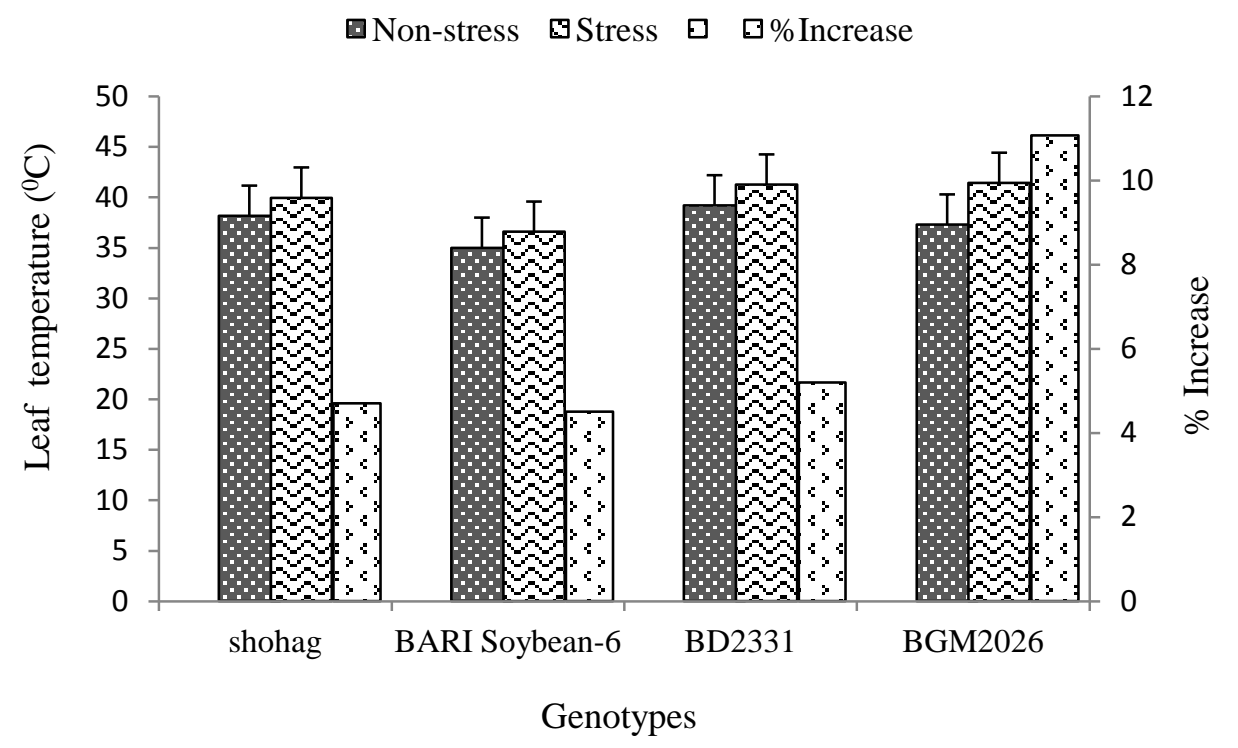

Figure 9. Leaf temperature in four soybean genotypes grown under non-stress and water stress conditions at pod development stage [Vertical bar represent LSD value at $5 \%$ level of significant]

\section{CONCLUSION}

Based on findings of the present study it may concluded that high water stress tolerance of Shohag, BARI Soybean-6, BD2331 is associated with maintaining better plant water relations which is reflected by higher relative water content, water retention capacity, exudation rate, lower leaf water potential and leaf temperature than in case of BGM2026. 


\section{REFERENCES}

Aguirre, J.F., RuizL, P.J., Kohashi-Shibata, J., Trejo-Lopez, C., and Acosta-Gallegos, J.A. (1999). Morphological observations in the leaf surface of Phaseolus vulgaris L. and their possible relationship to stomotal response. Annual Report of the Bean Improvement Cooperative, 42, 75-76.

Aziz, M.A. (2003). Growth, yield and some physiological mechanisms of salinity tolerance in mungbean. A Ph.D. Dissertation. Department of Agronomy, Bangabandhu Sheikh Mujibur Rahman Agricultural University, Gazipur, Bangladesh, p. 127.

Choudhury, A.K. (2009). Water stress tolerance of french bean (Phaseolus vulgaris L.). $\mathrm{Ph}$. D. Dissertation. Department of Agronomy, Bangabandhu Sheikh Mujibur Rahman Agricultural University, Salna, Gazipur-1706. Bangladesh.

Ehrler, W.L., Idso, S.B., Jackson, R.D., and Reginato, R.J. (1978). Wheat canopy temperature: Relation to plant water potential. Agronomy Journal, 70, 251-256.

Gonzales, L., and Gonzales-Vilar, M. (2001). Determination of relative water content. In: Reigosa M.J. (ed.). Handbook of plant Ecophysiology Techniques, Dordrecht: Kluwer Academic Publishers, p. 207-212.

González, A., Martín, I. and Ayerbe, L. (2008). Yield and osmotic adjustment capacity of barley under terminal water-stress conditions. Journal of Agronomy and Crop Science, 194, 81-91.

Khan, M.S.A. (2013). Evaluation of soybean genotypes in relation to yield perfopmance, salinity and drought tolerance. A Ph.D. Dissertation. Department of Agronomy, Bangabandhu Sheikh Mujibur Rahman Agricultural University, Gazipur, Bangladesh, p. 7

Makbul, S., Guler, N.S., Durmus, N., and Guven, S. (2011). Changes in anatomical and physiological parameters of soybean under drought stress. Turkey Journal of Botany, 35, 369-377.

Nayyer, H., Kaur, S., Singh, K.J., Dhir, K.K., and Bains, T. (2005). Water stress induced injury to reproductive phase in chickpea: evaluation of stress sensitivity in wild and cultivated species in relation to abscisic acid and poly amines. Journal of Agronomy and Crop Science, 191, 450-457.

Ocampo, E.T.M., and Robles, R.P. (2000). Drought tolerance in Mungbean II. Stomatal Movement, Photosynthesis and leaf water potential. Philippine Journal of Crop Science, 25, 7-15.

Ohashi, Y., Saneoka, H., and Fujita, K. (2000). Effect of water stress on growth, photosynthesis and photoassimilate translocation in soybean and tropical pasture legume siratro. Soil Science and Plant Nutrition, 46, 417- 425.

Omae, H., Kumar, A., Egawa, Y., Kashiwaba, K., and Shono, M. (2005). Midday drop of leaf water content to drought tolerance in snap bean (Phaseolus vulgarid L.). Plant Production Science, 8, 465-467.

Omae, H., Kumar, A., Kashiwaba, K., and Shono, M. (2007). Assessing drought tolerance of snap bean (Phaseolus vulgaris) from genotypic differences in leaf water relations, shoot growth and photosynthetic parameters. Plant Production Science, 10, 28-35. 
Onwugbuta-Enyi, J. (2004). Water balance and proximate composition in cowpea (Vignaunguiculata (I) Walps) seedlings exposed to drought and flooding stress. Journal of Applied Science and Environmental Management, 8, 55-57.

Parsons, L.R., and Howe, T.K. (1984). Effects of water stress on the water relatins of Phaseolus vulgaris and the drought resistant Phaseolus acutifolius. Physiology of Plant, 60,197-202.

Rosales-Serna, R., Kohashi-Shibata, J., Acosta-Gallegos, J. A., Trejo-Lopez, C., OrtizCerceres, J., and. Kelly, J.D. (2004). Biomas distribution, maturity acceleration and yield in drought-stressed common bean cultivars. Field Crops Research, 85, 203-2011.

Schonfeld, M.A., Johnson, R.C., Carver, B.F., and Mornhinweg, D.W. (1988). Water relations in winter wheat as drought resistance indicators. Crop Science, 28, 526-531.

Siddique, M.R.B., Hamid, A., and Islam, M.S. (2000). Drought stress effects on water relations of wheat. Botanical Bulletin of Academia Sinica, 41, 35-39.

Upreti, K. K., Murti, G.S.R and Bhatt, R.M. (2000). Response of pea cultivars to water stress: changes in morpho-physiological characters, endogenous hormones and yield. Vegetable Science, 27, 57-61.

Winter, S.R., Musick, J.T., and Porter, K.B. (1988). Evaluations of screening techniques for breeding drought-resistant winter wheat. Crop Science, 28, 512-516. 